\title{
Are we training junior doctors to respond to major incidents? A survey of doctors in the Wessex region
}

\author{
S N Madge, J P Kersey, G Murray, J R Murray
}

Emerg Med J 2004;21:577-579. doi: 10.1136/emj.2002.004606

Objective: To assess the current status of awareness and training of junior medical staff in the Wessex region in the event of a "conventional" major incident.

Methods: A telephone questionnaire of specialist registrars (SpRs) (or equivalent, for example, staff grade) in six core specialties was performed in all the 11 acute hospitals in the Wessex region on the same evening. This group was selected to represent a sample of the most senior medical staff "on site" at each hospital.

Results: 56 of 64 (87.5\%) SpRs participated. Nine of the 56 (16\%) SpRs questioned had previously been involved in a major incident, and 18 (32\%) had experienced some form of major incident training exercise. Subgroup analysis of the specialties showed that although there were no significant differences in numbers of training experiences between specialties, only one of nine (11\%) orthopaedic SpRs had ever been involved in a training exercise. Twenty five of the $56(45 \%)$ SpRs felt that they were confident of their role in the event of an incident.

Conclusion: Most middle grade staff in Wessex were not confident of their role in the event of a major incident. Most SpRs questioned had never attended a major incident training exercise.

$M$ ajor incidents are fortunately rare occurrences. However, careful planning and training are vital to adequately prepare individual NHS hospitals for such events. ${ }^{1}$ Insufficient staff training has been previously identified as a problem in the preparation of hospitals for major incidents, ${ }^{23}$ and has been highlighted as an area of weakness in the recent National Audit Office report ${ }^{1}$ on the readiness of the NHS for such events.

The 11 NHS hospitals in Wessex have their own distinct plans in the event of a major incident. ${ }^{4}$ In this pilot study, oncall medical staff at specialist registrar (SpR) grade (or equivalent) in six different disciplines at all 11 hospitals were contacted and questioned regarding their training and readiness for a potential "conventional" major incident. Training for chemical, nuclear, biological, and radiation incidents require specialised training and were not specifically discussed.

\section{METHOD}

Each acute hospital in the Wessex area (see box) was contacted by telephone on the evening of 20 November 2002. Although bias is a potential problem with telephone questionnaires, such a method was used to reflect the status quo at a point in time, and also to maximise responses from the subject group. Only doctors in the following six specialties who were physically "on site" at the time and consented were recruited into the study: accident and emergency, trauma and orthopaedics, general surgery, anaesthetics, general medicine, and paediatrics. These specialties were chosen to reflect a large sample of the disciplines required in the event of a major incident, each forming an integral part of hospitals' contact lists in the event of such an occurrence. In each specialty, the most senior clinician available on site was asked to participate in the study; in the vast majority of cases, this was usually a SpR.

To minimise possible bias, a standardised list of questions was used to ask SpRs about their grade, year, and length of experience at their individual hospitals. Each doctor was then questioned regarding their previous exposure to major incidents and training exercises for such events, at either their current or previous hospitals. Two further standardised questions were posed:

- "In the event of a major incident being declared this minute, would you be confident in your role?"

- "Do you know where to find out more about your hospital's major incident plan?"

To minimise disruption during a busy on call period, interviews were limited to the above questions only.

\section{RESULTS}

A total of 64 SpRs (or equivalents) at the 11 hospitals were contacted (in each of paediatrics and accident and emergency, there was only one SpR between Poole and Bournemouth hospitals). Altogether 56 of 64 (87.5\%) consented to participate at the time of the study. Table 1 shows the numbers of staff in the different specialties participating in the study, in addition to their average length of service at the hospital and year since attaining SpR grade (or equivalent, for example, staff grade). Senior house officers who were "acting up" on the registrar duty roster, and who were the most senior doctor available in the

\section{Acute hospitals in the Wessex area}

- Royal United Hospital, Bath

- St Mary's Hospital, Newport

- Poole Hospital, Poole

- Royal Bournemouth Hospital, Bournemouth

- Dorset County Hospital, Dorchester

- Princess Margaret Hospital, Swindon

- Royal Hampshire County Hospital, Winchester

- The North Hampshire Hospital, Basingstoke

- Queen Alexandra Hospital, Portsmouth

- Salisbury District Hospital, Salisbury

- Southampton General Hospital, Southampton 
Table 1 Details of participants in the study

\begin{tabular}{|c|c|c|c|c|c|c|}
\hline \multirow[b]{2}{*}{ Specialty } & \multirow{2}{*}{$\begin{array}{l}\text { Number of SpRs } \\
\text { participating }\end{array}$} & \multirow[b]{2}{*}{$\%$ Participation } & \multicolumn{2}{|c|}{$\begin{array}{l}\text { Average time at } \\
\text { hospital }\end{array}$} & \multicolumn{2}{|c|}{$\begin{array}{l}\text { Average year of } \\
\text { doctor (SpR or } \\
\text { equivalent) }\end{array}$} \\
\hline & & & Year & Months & Years & Months \\
\hline Accident and emergency & $10 / 10$ & 100 & 4 & 1 & 2 & 10 \\
\hline Trauma and orthopaedics & $9 / 11$ & 82 & 1 & 8 & 4 & 4 \\
\hline General surgery & $8 / 11$ & 73 & 0 & 6 & 3 & 1 \\
\hline Anaesthetics & $11 / 11$ & 100 & 0 & 7 & 2 & 0 \\
\hline General medicine & $11 / 11$ & 100 & 0 & 10 & 1 & 8 \\
\hline Paediatrics & $7 / 10$ & 70 & 2 & 10 & 2 & 8 \\
\hline
\end{tabular}

hospital, were designated "year 0", although their length of hospital service was not changed. One consultant was resident at the time of the study; this was a paediatric consultant with five years experience in this grade, increasing the mean "year" of paediatrician participating in the study from 1 year 4 months to 2 years 8 months.

Table 2 details SpRs' exposure to major incidents and training exercises. Also shown are the numbers of SpRs confident in their role and those knowing where more information about their role could be found

Of the 56 SpRs questioned, 9 (16\%) had been involved in a major incident, with an average of 2 years 10 months since such an event. Examples of such incidents include major traffic accidents, a bomb explosion in a public house, and terrorist related explosions in Northern Ireland. No doctor questioned had been involved in two or more major incidents.

Of the 56 SpRs, 18 (32\%) had previously been involved in a major incident training exercise. Exercises ranged from departmental seminars with the hospital's major incident officer, to half day sessions involving actors with fake injuries. The average length of time since the last training exercise in this group was 1 year 10 months (standard deviation 1 year 6 months). Three SpRs had been involved in more than one training exercise.

There was no significant disparity between the different specialties' exposure to major incident training exercises. Attention is however drawn to the fact that only one of the nine $(11 \%)$ participating orthopaedic SpRs had been involved in a training exercise.

There were significant differences between doctors in the different specialties concerning their confidence in their role during a major incident $\left(\chi^{2}\right.$ test, $\left.\mathrm{p}=0.02\right)$; no general surgical SpR questioned felt confident about their role in a potential major incident. Overall, 25 of 56 (45\%) SpRs felt that they were confident of their role in the event of an incident, but $40(71 \%)$ knew where more information regarding their role could be found.
Of the 10 accident and emergency SpRs, 8 (80\%) expressed confidence in their role in a major incident, with the same number knowing where more information concerning their role could be found. Five ( $50 \%$ ) had previously been involved in a training exercise.

There was no significant difference between individual hospitals with respect to their doctors' training experiences. However, two hospitals were identified where no doctors questioned had ever been involved in a major incident training exercise. Each of these two hospitals' staff had a $100 \%$ participation rate in the study.

\section{DISCUSSION}

In this study, less than a third of the middle grade on call doctors expected to participate in the response to a major incident had previously been involved in a training exercise, a figure similar to that reported in a survey of the South East Thames region performed in 1994. ${ }^{3}$ However, such a figure does not necessarily imply that the Wessex hospitals' training for such eventualities is substandard; it is certainly possible that their junior doctors had not attended such training sessions.

Less than half of all staff questioned expressed confidence in their role in a major incident. Confidence in one's own abilities is clearly a subjective value, which almost certainly introduces a degree of bias into the question; it is indeed easy to focus on the negative aspects. However, as compared with other specialties, general surgical SpRs were identified as having significantly less confidence in their putative role. It is not clear why this should be, but as with orthopaedic SpRs' low involvement in training exercises, this statistic may represent time pressures and other commitments. Seventy three per cent of SpRs, however, knew where more information could be found to improve their knowledge about their hospital's individual plan.

Although the Wessex region has a lower population than other parts of the country, there is no reason to suggest that its doctors are unusual in any sense with respect to the above results. The region contains a teaching hospital and 10 acute

\begin{tabular}{lllll} 
Table 2 & Specialist registrars' exposure to major incidents and training exercises \\
\hline & $\begin{array}{l}\text { SpRs previously } \\
\text { involved in major } \\
\text { incidents }\end{array}$ & $\begin{array}{l}\text { SpRs previously } \\
\text { involved in } \\
\text { training } \\
\text { exercises }\end{array}$ & $\begin{array}{l}\text { SpRs confident } \\
\text { of own role in } \\
\text { a major incident }\end{array}$ & $\begin{array}{l}\text { SpRs knowing } \\
\text { where to find } \\
\text { out more }\end{array}$ \\
Specialty & $2 / 10(20)$ & $5 / 10(50)$ & $8 / 10(80)$ & $8 / 10(80)$ \\
\hline $\begin{array}{l}\text { Accident and } \\
\text { emergency }\end{array}$ & $2 / 9(22)$ & $1 / 9(11)$ & $3 / 9(33)$ & $4 / 9(44)$ \\
$\begin{array}{l}\text { Trauma and } \\
\text { orthopaedics }\end{array}$ & $1 / 8(13)$ & $2 / 8(25)$ & $0 / 8(0)$ & $7 / 8(88)$ \\
$\begin{array}{l}\text { General surgery } \\
\text { Anaesthetics }\end{array}$ & $2 / 11(18)$ & $5 / 11(45)$ & $6 / 11(55)$ & $8 / 11(73)$ \\
$\begin{array}{l}\text { General medicine } \\
\text { Paediatrics }\end{array}$ & $0 / 11(0)$ & $2 / 11(18)$ & $6 / 11(55)$ & $8 / 11(82)$ \\
\hline & $2 / 7(29)$ & $3 / 7(43)$ & $2 / 7(29)$ & $5 / 7(71)$ \\
\hline Percentages are shown in parentheses. & & &
\end{tabular}


district general hospitals, employing many staff who have previously worked in different regions and countries. The study was deliberately performed out of normal working hours to concentrate on the individual hospitals' initial responses to an unexpected incident at an inconvenient time, when staffing levels are low.

In conclusion, this study reinforces the results of previous studies, identifying a lack of training experiences and confidence of middle grade, resident staff in the Wessex area in the event of a conventional major incident. Further studies should be undertaken to establish the level of training in the nation as a whole.

\section{CONTRIBUTORS}

GM, JPK, and JRM had the original idea for the study. SNM and JRM wrote the original protocol and questionnaire. SNM coordinated the study. JPK, JRM, and SNM conducted the questionnaire and collected the data. SNM and JRM analysed the data. SNM wrote the original manuscript. All authors contributed to revisions of the manuscript. SNM will act as guarantor for the paper.

\section{Authors' affiliations}

S N Madge, Department of Ophthalmology, Royal United Hospital, Bath, UK
J P Kersey, Department of Ophthalmology, Southampton General Hospital, Southampton, UK

G Murray, Group Practice, St Andrew's Road, Tidworth, Salisbury, UK

J R Murray, Department of Trauma and Orthopaedics, Princess

Margaret Hospital, Swindon, UK

Funding: none.

Competing interests: none declared.

Correspondence to: Dr S N Madge, Department of Ophthalmology, Royal United Hospital, Combe Park, Bath BA1 3NG, UK; smadge007@ yahoo.co.uk

Accepted for publication 1 May 2003

\section{REFERENCES}

1 National Audit Office. Facing the challenge: NHS emergency planning in England. London: National Audit Office, 2002 (http://www. nao.gov.uk).

2 Nancekievill DG. On site medical services at major incidents. BMJ 1992;305:721-7.

3 Brennan L, Sage FJ, Simpson A. Major incident planning in South East Thames Region: a survey of medical staff awareness and training. J Accid Emerg Med 1994;11:85-9.

4 Carley S, Mackway-Jones K. Are British hospitals ready for the next major incident? Analysis of hospital major incident plans. BMJ 1996;313:1242-3. 